\title{
Intermetallic Phase Growth in Al-steel Clad Strip during In-situ Heating in TEM
}

$\underline{\text { Barbora Křivská }}^{1}$, Michaela Šlapáková ${ }^{1}$, Peter Minárik ${ }^{1}$, Klaudia Fekete ${ }^{1}$, Rostislav Králík ${ }^{1}$, Mykhailo Stolbchenko $^{2}$, Mirko Schaper ${ }^{2}$ and Olexandr Grydin ${ }^{2}$

${ }^{1}$ Charles University, Faculty of Mathematics and Physics, Prague, Czech Republic.

${ }^{2}$ Paderborn University, Chair of Materials Science, Paderborn, Germany.

The cladding strips consisting of different metals enables to obtain a material with a unique combination of properties, which cannot be achieved by conventional materials. Joints of stainless steel and Al are the most widely used commercial composites since they combine high strength of the steel with a low density of $\mathrm{Al}[1,2]$. Twin-roll casting is a new method of clad sheet production [2,3], which is based on a direct pouring of the $\mathrm{Al}$ melt on a steel substrate and their simultaneous feeding between cooled rolls of a caster. The twin-roll cladding reduces the number of production steps - directly related to energy consumption and costs - compared to commercially used roll-bonding methods requiring the production of single monolayers before the cladding process.

The clad strips are often subjected to thermal exposure when they are manufactured, so a diffusion is enhanced between the metals. As a consequence, a brittle Al-Fe rich intermetallic layer can form at the interface between $\mathrm{Al}$ and steel, resulting in a deterioration of composite mechanical properties [4,5]. Therefore, the formation and kinetics of the Al-Fe rich intermetallic layer was studied during in-situ annealing in TEM.

Twin-roll cladding of the Al-steel clad sheets resulted in a joint without any continuous intermetallic layer at the interface between the $\mathrm{Al}$ and steel layer. Several pores occurred on the interface between $\mathrm{Al}$ and steel due to a presence of microscopical grooves in the steel substrate. The surface tension of the Al melt then did not allow to create a flawless contact between the liquid Al and the solid steel strip.

The first in-situ experiment was performed using transmission electron microscope JEOL JEM 2000F (in SEM mode) revealing the direction of diffusion and related intermetallic phase growth. Before the in-situ annealing, a carbon marker was created by a focused electron beam near the Al-steel interface (on the Al side) to define the initial position of the interface. Then, the temperature was increased slowly and no changes in the region around the interface were observed up to $500{ }^{\circ} \mathrm{C}$ when an abrupt formation of the intermetallic layer emerged in the direction towards the steel substrate (Fig. 1). The kinetics of the intermetallic layer formation was investigated using transmission electron microscope JEOL JEM 2200FS. The temperature was slowly increased up to $540{ }^{\circ} \mathrm{C}$ and then set constant. Since the formation of the intermetallic layer was not continuous, the effective thickness $d_{\text {eff }}$ of the layer was evaluated from the overall area taken by the layer divided by the length of the interface. The resulting time evolution of the effective thickness approaches so-called S-shape curve (Fig. 2): the first stage corresponds to the formation of individual discontinuous nuclei; in the middle stage the rate of the phase formation increases; and during the final part of the in-situ annealing, the growth of the layer is saturated. The results show that the phase growth is a diffusion-controlled phase transformation following a parabolic law [6,7] modified by a partial delamination of the layers detected when the continuous layer was formed on the interface. 


\section{References:}

[1] P Groche et al, Process. Technol. 214 (2014), p. 1972.

[2] O Grydin et al, J. Manuf. Process. 15 (2013), p. 501.

[3] M Stolbchenko et al, Forschung im Ingenieurwesen 78 (2014) p. 121.

[4] HR Akramifard, H Mirzadeh and MH Parsa, Mater. Sci. Eng. A 613 (2014), p. 232.

[5] JY Jin and SI Hong, Mater. Sci. Eng. A 596 (2014), p. 1.

[6] H Springer et al, Acta Mater. 59 (2011), p. 1586.

[7] R Li et al, Scr. Mater. 110 (2016), p. 105.

[8] The financial support of GAČR project 20-00355Y, SVV-260582 and German Research Foundation (DFG) in regard to the project SCHA 1484/21-1 are highly acknowledged.
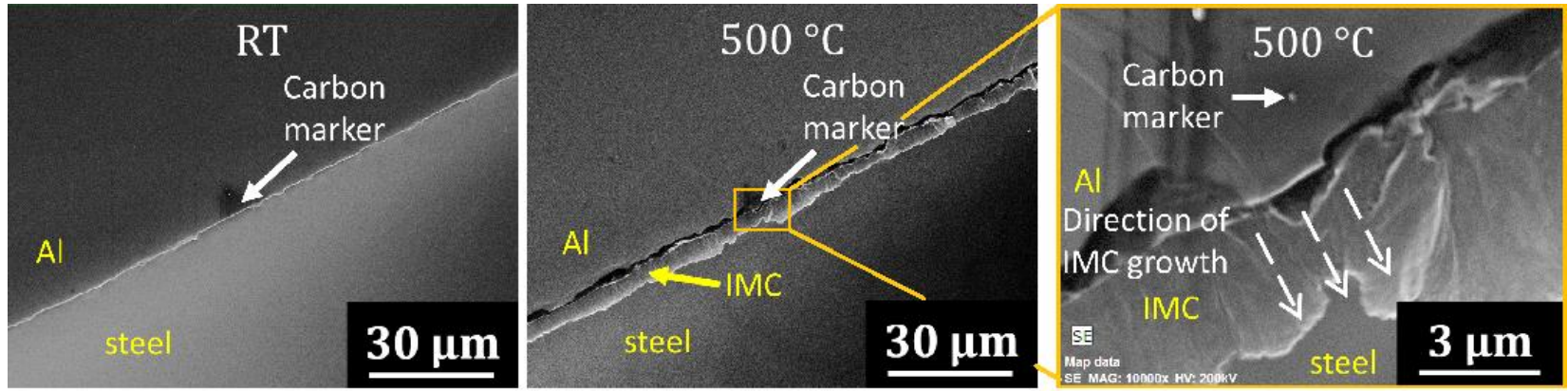

Figure 1. In-situ annealing in TEM (in SEM mode). According to the position of the carbon marker, the intermetallic (IMC) layer grew towards the steel layer.
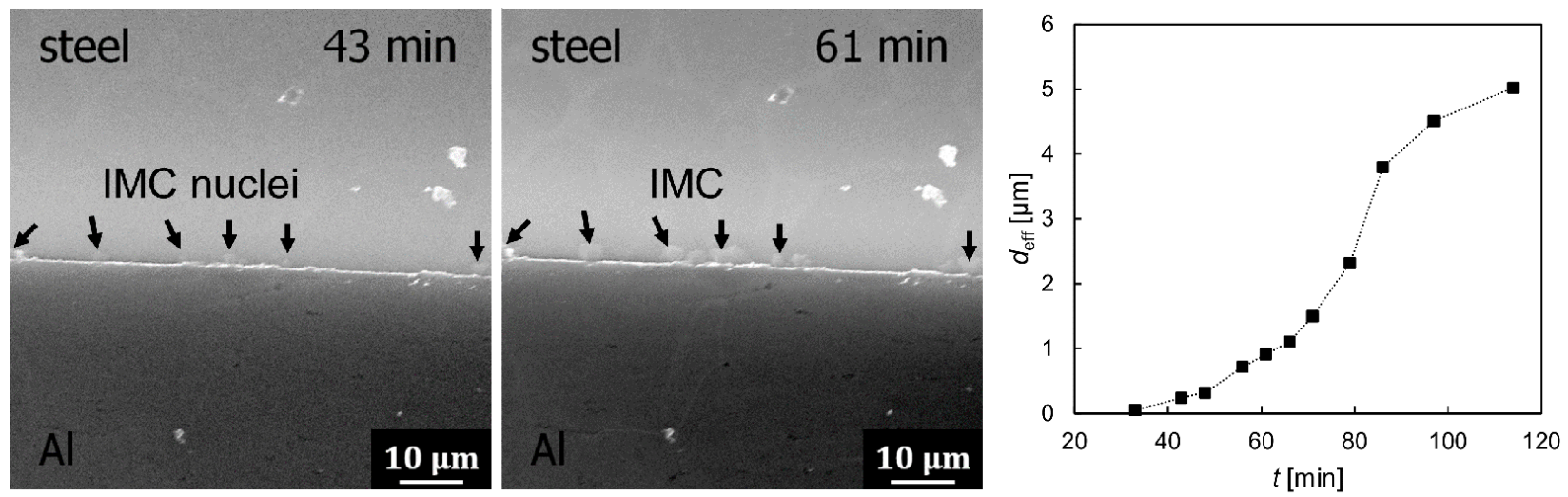

Figure 2. In-situ annealing in TEM (in SEM mode). The intermetallic phase formation was monitored during annealing at $540{ }^{\circ} \mathrm{C}$. S-shape curve describes the nucleation and growth of the intermetallic phase. 